\title{
Penyuluhan dan Pendampingan pada Korban Selamat Percoban Bunuh Diri di Gunung Kidul
}

\author{
Fatwa Tentama ${ }^{*}$, Surahma Asti Mulasari ${ }^{2}$, Tri Wahyuni Sukesi ${ }^{3}$, Sulistyawati ${ }^{4}$ \\ ${ }^{1234}$ Fakultas Kesehatan Masyarakat Universitas Ahmad Dahlan Yogyakarta
}

\section{A R T I C L E I N F O}

Article history:

Received 20 December 2018

Received in revised form 1 January 2019

Accepted 30 January 2019

Available online 27

February 2019

\section{Kata Kunci:}

penyuluhan, pendampingan, bunuh diri

Keywords:

counseling, mentoring, suicide

\begin{abstract}
A B S T R A K
Bunuh diri saat ini sudah menjadi masalah global. Menurut WHO tahun 2015 lebih dari 800.000 orang/tahun meninggal karena bunuh diri. Jumlah rata-rata penduduk Indonesia yang meninggal akibat bunuh diri mencapai 24 per 100.000 penduduk. Saat ini kasus bunuh diri di Gunungkidul bergeser ke usia produktif. Meningkatnya kasus bunuh diri di Gunungkidul menjadi suatu permasalahan yang harus ditangani bersama. Tujuan dari kegiatan ini adalah untuk meningkatkan pengetahuan, dan kesehatan jiwa bagi korban selamat, keluarga, dan masyarakat di Gunungkidul dan untuk mencegah meningkatnya angka bunuh diri di Gunungkidul. Metode yang diterapkan dalam kegiatan ini adalah penyuluhan dan pendampingan. Dampak yang diperoleh adalah peningkatan pengetahuan keluarga dan masyarakat mengenai ketahanan jiwa dan peran yang bisa dilakukan dalam mencegah adanya tindakan bunuh diri di lingkungan sekitar, selain itu diharapkan adanya pemulihan tekanan psikologis maupun rohani pada korban agar tidak ingin melakukan tindakan bunuh diri kembali.
\end{abstract}

A B S T R A C T

Suicide is a global problem. According to the WHO in 2015 more than 800,000 people / year died from suicide. The average number of Indonesians who died from suicide reached 24 per 100,000 inhabitants. at present the suicide case in Gunungkidul shifts to productive age. The increase in suicides in Gunungkidul is a problem that must be dealt with together. The purpose of this activity is to increase knowledge, and mental health for survivors, families, and communities in Gunungkidul and to prevent rising suicide rates in Gunungkidul. The method applied in this activity is counseling and mentoring. The impact gained is an increase in family and community knowledge about endurance and the role that can be taken in preventing suicide in the surrounding environment, in addition it is expected to restore psychological and spiritual pressure to the victim so as not to commit suicide again.

\footnotetext{
* Corresponding author.

E-mail addresses: fatwa.tentama@psy.uad.ac.id (Fatwa Tentama)
} 


\section{Pendahuluan}

Bunuh diri menjadi masalah global. Menurut WHO tahun 2015 lebih dari 800.000 orang/tahun meninggal karena bunuh diri. Di Amerika Serikat bunuh diri remaja merupakan penyebab kematian kedua pada tahun 2013 (Centre For Disease Control and Prevention, 2016). Jumlah rata-rata penduduk Indonesia yang meninggal akibat bunuh diri mencapai 24 per 100.000 penduduk dengan kata lain sebanyak 50.000 orang dalam satu tahun. Prevalensi ini cenderung meningkat setiap tahunnya. Angka ini hampir mendekati angka bunuh diri yang terjadi di China yakni berjumlah 250.000 dan di India 100.000 orang dalam waktu satu tahun (Vijayakumar \& Nagarai, 2004).

Fenomena bunuh diri masyarakat di Gunungkidul, Provinsi Daerah Istimewa Yogyakarta (DIY), dikaitkan dengan adanya sebagian masyarakat yang mempercayai mitos Pulung Gantung. Pulung Gantung adalah semacam bola api yang akan muncul pada malam hari yang dipercayai apabila jatuh di suatu rumah maka salah satu penghuni rumah tersebut akan melakukan gantung diri atau bunuh diri (Andari, 2017).

Namun demikian seiring dengan perkembangan penelitian yang dilakukan kepercayaan tersebut terkikis dengan beberapa data terbaru yang menyebutkan bahwa motivasi melakukan bunuh diri sebagian besar dipicu oleh depresi (Okenews, 2019). Diperkirakan sebanyak 15\% orang-orang yang didiagnosis menderita depresi berat akhirnya bunuh diri (Davison dkk., 2006). Saat ini kasus bunuh diri di Gunungkidul bergeser ke usia produktif (Kompas, 2017). Relawan LSM imaji (Inti Mata Jiwa), Sigit Wage Dhaksinarga mengatakan bahwa data tahun 2017 angka bunuh diri tak lagi didominasi usia tua, tetapi sudah ke usia produktif antara 25-50 tahun. Selain itu dari hasil penelitian Wage penelitiannya sejak tahun 2010 menyimpulkan bahwa saat ini kasus bunuh diri di Gunung kidul tidak bisa dilihat dari ekonomi dan religious (Kompas, 2017).

Penyebab kasus bunuh diri di Gunungkidul sangat kompleks dan salah satu penyebabnya diantaranya depresi. Data terakhir yang bersumber dari polres Gunungkidul menunjukkan data bahwa tahun 2015 data korban gantung diri mencapai 33 orang dan tahun 2016 ini dalam empat bulan terakhir (Januari-April 2016) jumlah korban gantung diri sudah mencapai 14 orang. Data menunjukkan bahwa penyebab utama seseorang melakukan gantung diri adalah putus asa yang akhirnya menyebabkan depresi (Kedaulatan Rakyat, 2016). Gantung diri memang tidak secara langsung berhubungan dengan masalah kesehatan, namun proses penyebabnya merupakan rangkaian masalah kesehatan mental yaitu depresi. Menurut dokter Ida seseorang yang melakukan percobaan gantung diri disebabkan karena perubahan perilaku dan adanya riwayat gangguan jiwa sebelumnya (Kedaulatan Rakyat, 2016). Dari literatur disebutkan gantung diri yang terjadi diantaranya disebabkan sakit menahun yang tiada kunjung sembuh, sehingga merasa membebani keluarga, tekanan ekonomi, hidup sebatangkara, tidak diurus keluarga yang akhirnya menimbulkan depresi pada diri seseorang. Saat ini yang sangat didiperlukan penyuluhan dan pendampingan pada masyarakat setempat dan juga pada korban selamat bunuh diri agar perilaku bunuh diri tidak terjadi lagi.

\section{Metode}

Metode yang diterapkan dalam program kegiatan pengabdian masyarakat ini adalah penyuluhan dan pendampingan. Penyuluhan dilakukan dengan metode ceramah, diskusi dan tanya jawab. Metode ceramah adalah suatu cara dalam menerangkan dan menjelaskan suatu ide, pengertian atau pesan secara lisan kepada sekelompok sasaran sehingga memperoleh informasi mengenai kesehatan (Notoatmojo, 2010). Pendampingan dilakukan dengan metode konseling dan wawancara mendalam pada korban. Kegiatan dilaksanakan pada bulan Maret - Desember 2018. Sasaran kegiatan pengabdian ini adalah Lima korban selamat bunuh diri, keluarga korban selamat dan teman sebaya korban selamat di Desa Karangwungu Kecamatan Tepus, Gunung Kidul.

\section{Hasil dan pembahasan}

Manajemen CV. Bintang Lima Mahardikka

Berdasarkan hasil observasi dan wawancara mendalam dengan para korban selamat bunuh diri, diperoleh informasi bahwa hampir semua korban bunuh diri ini melakukan bunuh diri karena adanya masalah yang menyebabkan depresi. Depresi merupakan masalah kesehatan yang sangat serius (Blazer, 2000). WHO mengatakan depresi adalah gangguan mental yang ditandai dengan adanya perasaan sedih, kehilangan minat atau kesenangan, penurunan energi, perasaan bersalah atau rendah diri. Depresi biasanya berbanding linier dengan kejadian bunuh diri (WHO, 2012). 
Depresi sudah menjadi faktor utama pada penyebab bunuh diri (Greydanus et. al, 2009). Hasil wawancara menunjukkan ada beberapa faktor pemicu terjadinya depresi yaitu ketidakberdayaan dan kesedihan yang mendalam karena kehilangan pekerjaan, suami dan anak pada waktu yang hampir bersamaan. Adanya trauma setelah kehilangan salah satu anggota badan yang terpaksa diamputasi, sejarah masa lalu yang sering mengalami bulliying sejak kecil dan adanya penolakan dari masyarakat.

Kaplan menyatakan bahwa faktor penyebab depresi dapat dibagi menjadi faktor biologi, faktor genetik, dan faktor psikososial (Kaplan et.al, 2010). Depresi disebabkan oleh keputusasaan, tekanan psikologis, masalah yang dihadapi, kurang memperoleh perhatian, masalah pertemanan/bullying, harga diri rendah, tekanan sosial dan ekonomi, bosan hidup, putus asa, kesehatan, kematian seseorang, takut masa depan, dan kegagalan. Sehingga seseorang memutuskan untuk melakukan bunuh diri (Pratiwi \& Undarwati, 2014).

Modus yang dilakukan untuk bunuh diri dari 5 responden ini juga bermacam macam, ada yang akan menceburkan diri ke dalam sumur, gantung diri dan meminum racun. Masalah utama yang terdapat di Gunungkidul yaitu bunuh diri, maka dilakukan upaya pencegahan dan pengendalian dengan cara melakukan penyuluhan dan memberikan pendampingan berupa konseling kepada korban selamat bunuh diri di Gunung kidul.

Kegiatan pengabdian ini telah terlaksana pada bulan maret - oktober 2018 di Desa Karangwungu Kecamatan Tepus, Gunung Kidul. Rangkaian kegiatan pengabdian ini adalah pemberian penyuluhan kepada korban selamat, keluarga dan sahabat terdekat mengenai kesehatan jiwa yang dibagi menjadi 4 sesi. Pada sesi pertama menjelaskan tentang kebahagiaan hidup dan manfaatnya bagi psikologi manusia dengan narasumber Farwa tentama. Sesi kedua menjelaskan tentang peran perempuan terutama ibu, istri atau anak dalam mencegah depresi khususnya gantung diri dengan narasumber Tri wahyuni sukesi. Sesi ketiga dan ke empat di sampaikan oleh Yayasan Imaji dengan materi kesehatan jiwa dan penyakit jiwa.
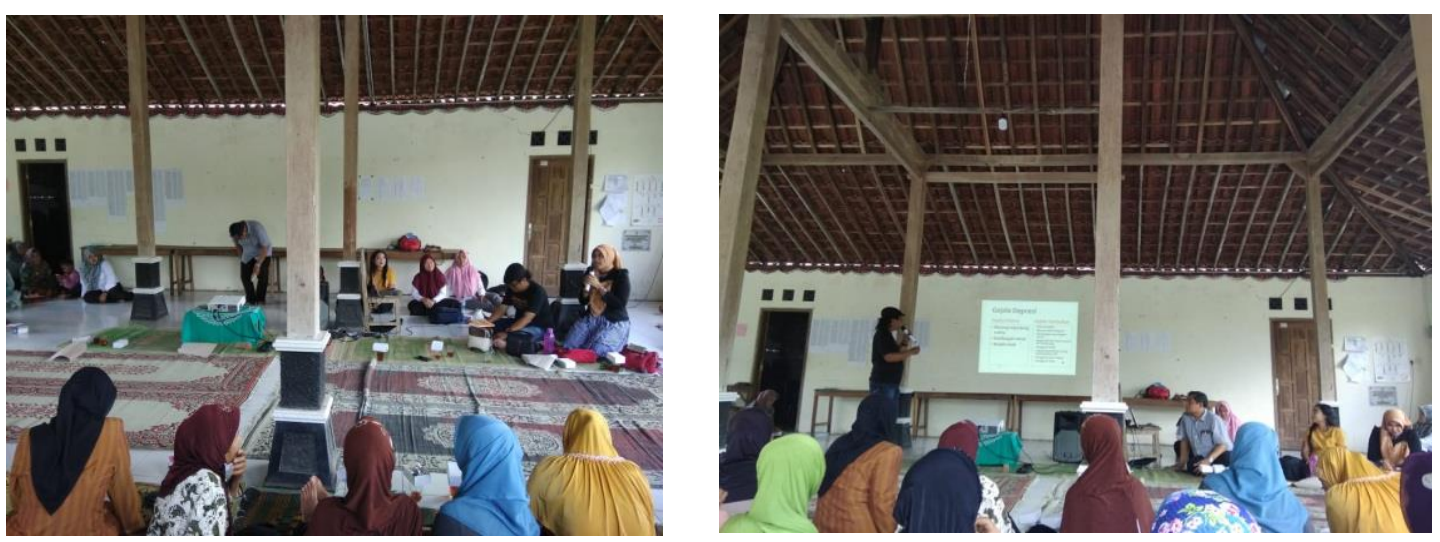

Gambar 1. Penyampaian Materi oleh Narasumber

Pemberian penyuluhan merupakan upaya preventif khususnya mengenai kesehatan jiwa bertujuan untuk mencegah terjadinya masalah kejiwaan, mencegah timbul dan/atau kambuhnya gangguan jiwa, mengurangi faktor risiko akibat gangguan jiwa pada masyarakat secara umum atau perorangan, serta mencegah timbulnya dampak masalah psikososial yang dilaksanakan di lingkungan keluarga, lembaga, dan masyarakat (Undang-undang nomor 18 tahun 2014).

Salah satu solusi peredaman bunuh diri adalah dengan menggunakan terapi pendampingan psikososial atau terapi pendampingan berbasis keluarga (Firestone, 2007). Sehingga selain memberikan penyuluhan kesehatan, pengabdi juga melakukan pendampingan kepada korban selamat bunuh diri. Kegiatan pendampingan dilakukan untuk meyakinkan korban agar dapat menyadari keberadaan diri dan makna hidupnya, mengetahui peran dan fungsinya di tengah lingkungan sosial, serta menyadari potensipotensi diri yang dimilikinya untuk dikembangkan.

Pendampingan tidak hanya untuk memulihkan kesehatan jiwa namun juga kesehatan rohani korban. Terapi yang terbaik bagi keresahan adalah keimanan kepada Tuhan (Razak et.al, 2013). Sebuah penelitian menyebutkan bahwa terapi spiritual dan religius efektif mengatasi persoalan persoalan gangguan mental seperti kecemasan schizophrenia, dan depresi (Hook et.al, 2010). Pada kegiatan pendampingan, korban diajarkan untuk mengambil hikmah dari setiap kejadian, meningkatkan iman dan berserah diri kepada yang Maha Kuasa. Sehingga korban akan mendapatkan keikhlasan dan kesabaran dalam menghadapi cobaan serta semangat dalam menjalankan kehidupan. 
Perilaku bunuh diri mengacu pada pikiran-pikiran dan perilaku yang terkait dengan intensi individual untuk mengakhiri hidup mereka sendiri (O'Connor \& Knock, 2014). Kepercayaan terhadap Tuhan yang menjadi suatu kekuatan dari dalam dirinya untuk dapat memperbaiki kondisinya menjadi lebih baik (Satrianegara, 2014). Oleh karena itu penguatan dari sisi religi sangat diperlukan untuk menguatkan jiwa dan rohani perilaku bunuh diri yang menderita depresi agar segera keluar dari depresinya mengingat sebagian besar penyebab bunuh diri adalah depresi.
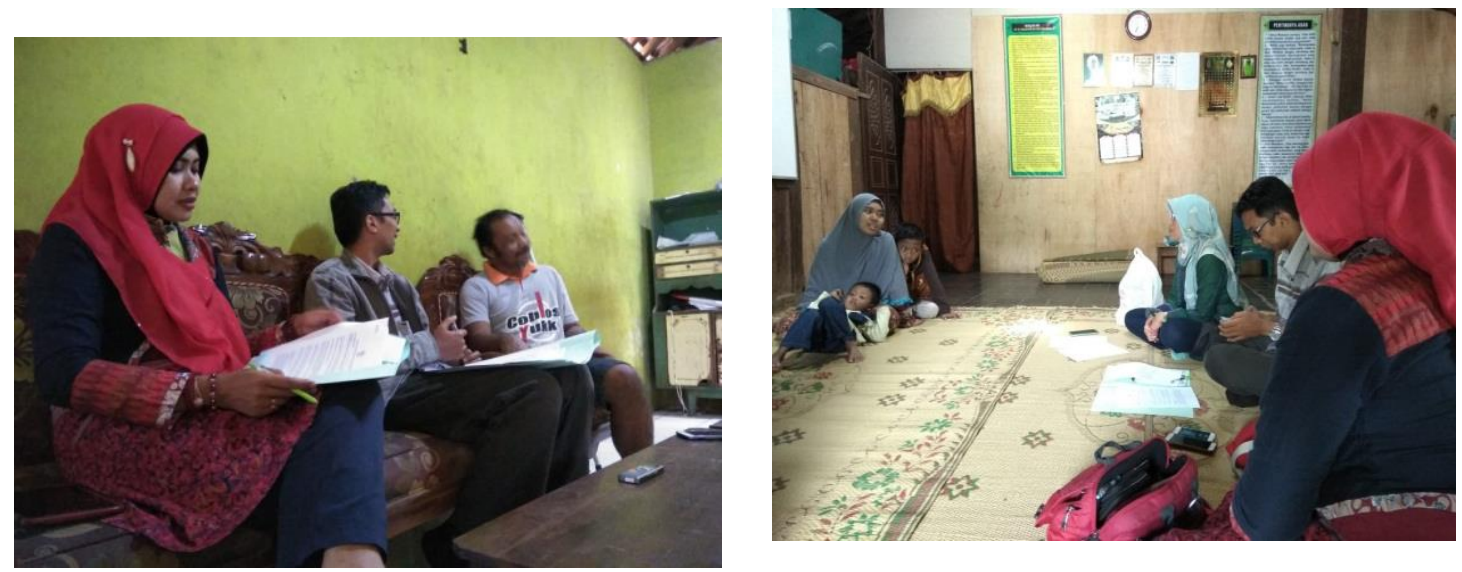

Gambar 2. Pendampingan Korban Selamat Bunuh Diri di Gunung Kidul

Secara teori, membina hubungan yang erat dengan pelaku, penuh perhatian, mendengarkan, menghargai perasaan serta memahami emosinya merupakan cara yang dapat mencegah tindakan bunuh diri (Nugrawati et.al, 2016). Hal ini dikarenakan tindakan tersebut dapat memberikan dukungan sosial dengan korban. Dukungan sosial cenderung memiliki relevansi khusus untuk pencegahan bunuh diri (Cho \& Haslam, 2010).

Perhatian atau dukungan sosial menjadi penting terutama ketika seseorang sedang mengalami keterpurukan atau masalah. Individu akan cenderung lebih kuat ketika ada seseorang menemaninya maupun untuk mendengarkan keluh kesahnya. Hal ini berbeda dengan individu yang hanya sendiri dalam menghadapi permasalahan dikarenakan beban, rasa sakit bahkan kemarahan yang dirasakan seolah-olah hanya dipikulnya sendiri sehingga menyerah pada hidup mungkin terlintas pada pikiran(Almeida, et.al, 2012).

Kegiatan pengabdian ini terlaksana dengan baik, hal ini dapat dilihat dari adanya respon positif dari korban selamat bunuh diri, keluarga, sahabat dan masyarakat pada saat dilakukan penyuluhan dan pendampingan. Pengabdian ini diharapkan agar dapat meningkatkan pengetahuan keluarga dan masyarakat mengenai ketahanan jiwa dan peran yang bisa dilakukan oleh keluarga dan masyarakat dalam mencegah adanya tindakan bunuh diri di lingkungan sekitar, selain itu pada korban diharapkan adanya pemulihan tekanan psikologis maupun rohani agar korban tidak ingin melakukan tindakan bunuh diri kembali.

\section{Simpulan dan saran}

Kegiatan Pengabdian telah berjalan dengan lancar. Melalui kegiatan penyuluhan telah diberikan edukasi kepada korban, keluarga dan masyarakat di gunung kidul tentang upaya-upaya yang dapat dilakukan untuk meningkatkan ketahanan jiwa bagi korban, keluarga dan masyarakat. Hal yang dapat dilakukan untuk mencegah terjadinya kasus bunuh diri yaitu membantu orang orang yang mengalami depresi untuk sembuh dan keluar dari depresinya. Penguatan dari sisi religi sangat diperlukan untuk menguatkan penderita depresi agar segera keluar dari depresinya.

Saran dari penelitian ini antara lain: 1) Pemerintah Kabupaten Gunungkidul bersama sama dengan masyarakat melakukan pendampingan pada orang orang yang mengalami depresi agar dapat menyelesaikan permasalahannya dan keluar dari depresinya.2) Pemerintah Kabupaten Gunungkidul bersinergi dengan masyarakat untuk melakukan pendidikan kesehatan jiwa di seluruh wilayah Gunungkidul, dan 3) Meningkatkan fungsi puskesmas yaitu bagian psikolog dan konseling agar orang orang yang membutuhkan konseling seorang psikolog dapat menjangkau dengan mudah pelayanan untuk kesehatan jiwa. 


\section{Daftar Rujukan}

Almeida, O. P., B. Draper, J. Snowdon, N. T. Lautenschlager, J. Pirkis, G. Byrne, M. Sim, N. Stocks, L. Flicker, dan J. J. P. (2012). Factors Associated with Suicidal Thoughts in A Large Community Study of Older Adults. The British Journal of Psychiatry.201, 466-472.

Andari, S. (2017). Fenomena Bunuh Diri di Kabupaten Gunung Kidul. Jurnal Sosio Konsepsia, 7(1), 92-107.

Centre For Disease Control and Prevention. (2016). Suicide. Retrieved from www.cdc.gov/ViolencePrevention/suicide/index.html

Cho, Y., \& Haslam, N. (2010). Suicidal Ideation and Distress Among Immigrant Adolescents: The Role of Acculturation, Life Stress, and Social Support. Journal Youth Adolescence, 39, 370-379. https://doi.org/10.1007/s10964-009-9415-y

Davison, G. C., Neale, J. M., \& Kring, A. M. (2006). Psikologi Abnormal. Penerjemah: Noermalasari Fajar. Jakarta: PT.Grafindo Persada.

Blazer, D., G. (2000). Mood Disorders: Epidemiology Comprehensive Textbook Of Psychiatry. Philadelphia: Lippincott Williams \& Wilkins.

Firestone, R. W. (2007). Suicide and The Inner Voice: Risk Assesment, Treatment, and Case Management. Los Angeles: SAGE Publications.

Greydanus, D. E., Bacopoulou, F., \& Tsalamanios, E. (2009). Suicide in Adolescents: A Worldwide Preventable Tragedy. Keio J Med, 58(2), 95-102.

Hook J. N., Worthington E. L., Jr, Davis D. E., Jennings D. J. 2nd, Gartner A. L., \& Hook J. P. (2010). Empirically Supported Religious and Spiritual Therapies. Journal of Clinical Psychology, 66(1), 4672.

Kaplan, H. I., Saddock, B. J., \& Grebb, J. A. (2010). Sinopsis Psikiatri: Ilmu Pengetahuan Perilaku Psikiatri Klinis. Jakarta: Bina Rupa Aksara.

Kedaulatan Rakyat. (2016). Misteri Pulung Gantung Belum Terungkap: Tinggi Angka BunuhDiri di Gunungkidul. Yogyakarta.

Kompas. (2017). Tren Kasus Bunuh Diri di Gunung Kidul Bergeser ke Usia Produktif. Retrieved from http://regional.kompas.com/read/2017/07/10/14440781/tren.kasus.bunuh.diri.di.\%0Agunungki dul. bergeser.ke.usia.produktif\%0A.

Notoatmojo. (2010). Ilmu Perilaku Kesehatan. Jakarta: PT Rineka Cipta.

Nugrawati, Nursalam, \& Akhir, M. (2016). Gantung Diri sebagai Penyimpangan Social Terhadap Norma Agama. Jurnal Equilibrium Pendidikan Sosiologi, 9(1), 11-19.

Undang-Undang Nomor 18 tahun 2014 Tentang Kesehatan Jiwa. Jakarta: Republik Indonesia.

O'Connor, R. C., \& Knock, M. K. (2014). Suicide 2. The Psychology Of Suicidal Behavior (1st ed.). Lancet Psychiatry.

Okenews. (2019). Karena Depresi, Banyak Warga Gunungkidul Bunuh Diri. Retrieved from https://news.okezone.com/read/2019/03/02/510/2024954/karena-depresi-banyak-wargagunungkidul-bunuh-diri.

Pratiwi, J. \& Undarwati, A. (2014). Suicide Ideation pada Remaja di Kota Semarang. Jurnal Developmental and Clinical Psychology, 3(1), 24- 34. 
Razak, A., Mokhtar, M. kamal, \& Sulaiman, W. S. W. (2013). Terapi Spiritual Islami Suatu Model Penanggulangan Gangguan Depresi. Jurnal Dakwah Tabligh, 14(1), 141-151.

Satrianegara, M. F. (2014). Pengaruh Religiusitas Terhadap Tingkat Depresi, Kecemasan, Stres dan Kulaitas Hidup Penderita Penyakit Kronis di Kota Makassar. Jurnal Kesehatan, VII(1), 288-304.

Vijayakumar, L., \& Nagarai, K. (2004). Suicide and Suicide Prevention in Developing Countries, Disease Control Priorities Project, p. 24.

WHO. (2012). Depression, A Global Public Health Concern. WHO Departemen Mental Health Substance Abuse, 6-8. 